\title{
CASE OF HOMONYMOUS HEMIANOPSIA, WITH POST-MORTEM APPEARANCES.
}

\author{
BY EDWIN I. DUNN, B.A., M.B., ETC. \\ Assistant Medical Officer, Wakefield Asylum.
}

M. A. S., æt. 43, was admitted to the Wakefield Asylum on December 15th, 1891.

History.-Patient has ben in the habit of giving way to bouts of alcoholic excess. For about a month before admission she had been drinking very heavily. About one week before admission she was noticed to be "paralyzed on the left side, the hand was drawn up and the leg useless." Nothing of her family history known.

On admission she was in a maniacal condition and raving wildly. No direct reply to queries conld be obtained. It was noticed that there was paresis of the left side, with slight rigidity of elbow and shoulder joint. The grasp of left hand was very weak in comparison with the right. She could walk only with assistance, and the left leg was raised with difficulty and set down with a jerk on the heel. There wes constant convulsive twitching of left leg and arm. The papils were equal and semidilated. Their reactions were normal.

December 28th, 1891. - It is noticed that there is anmsthesia (to prick of a pin) of the left side, strongly marked in arm and leg, but not so much in face. There is possible slight ptosis of the left eyelid.

January 3rd, 1892.-Pupils are equal, all reactions present. The tongue is protruded to the left side. Sensation in left arm and leg is much better, being almost normal. Plantar reflex not well marked on left side; more marked on right, where it is, perhaps, excessive. Knee-jerk present on both sides, more marked on left. No clonus either side.

10th January, 1892.-Patient is much calmer. There is no defect of hearing. Sensation to pin-prick normal. Plantar reflex is excessive on both sides. There is no clonus. Kneejerks normal. Rigidity of left arm almost disappeared. Grasp of left hand is weaker than right. There is no rigidity of left leg. 
The gait is sterdy, but the left leg is moved in rather a jerky fashion, and there is a tendency to come down on the heel. There is no facisl pelsy. The tongue is protruded quite straight.

Eyes.-There is left homonymous hemianopsia, the defect being limited to the lateral half fields of vision in each eye. There is no change in the hemianopsic field with colours red or green. There is no colour blindness. Wernicke's pupillary inaction sign is not present (the pupil contracts when light is thrown on the blind helf of the retina). Pupillary accommodative reflex present. Light reflex present, but sluggish. Concentrated light also sluggish. Consensuals present, but very sluggish in left. eye. Pupils do not dilate to skin stimulus; they dilate at once emotionally. All ocular movements are perfect.

January 15th, 1892.-Hemianopsis unchanged. She says her leg is " all right," bat complains that the left arm is stiff and the hand occasionally numb. She is fairly rational, but prone to emotionslism.

Jamuary 24th, 1892.-It is noticed that she is prone to drop pieces of bread, plates, dc., out of her left hand. She complains that it does not feel right. Grasp on both sides almost equal. She constantly leaves food which has dropped to the left side of her plate.

February 19th, 1892.-Mental condition and hemianopsia as before.

February 20th, 1892.-The left arm has never completely recovered its normal amount of motor power, but has always been slightly weaker than the right. Sensation to painful stimulus has remsined unimpaired. She now complains that the arm is very numb, and is getting weaker. She has intense right-sided headache.

February 25th, 1892.-The headsche has continued, the arm has become much weaker. Both pupils are widely dilated, light and consensual reflexes are present

February 26th, 1892.-Patient became suddenly maniacal last night. To-day she cannot respond to queries, and is raving continually.

March 4th, 1892.-Mental state as above. The left arm and leg have been gradually getting worse, and are now completely paralyzed. Knee-jerk is present in both legs, is perhaps slightly increased in left. Plantar reflex is absent in left, present in right. limb. There is some rigidity in paralyzed limbs, especially in the arm. Sensation cannot be tested owing to the mental staté.

March 16th, 1892.- Sensation to prick of a pin is fairly per- 
fect. She cannot tell what it is ; says it is a "razor." She can . just move left hand and can draw up the left foot one inch.

March 20th, 1892.- She had a slight stroke or syncopal fit yesterday. (Pallor, lividity, coldness of extremities, \&c.) The left pupil is now widely dilated. Reacts slowly to concentrated light. The right pupil is semi-dilated, reacts quickly to concentrated light. Both appear to accommodate slightly and sluggishly. The optic discs and retinas are found normal by ophthalmoscopic examination. The paralysis in arm and leg is incomplete as before. Sensation to painful stimulus appears perfect.

Aprit 2nd, 1892.-Died of pneumoniz, her condition not having otherwise changed.

Autopsy.-Cardiac valves and muscle healthy. Right lung congested with small spot of grey hepatization in middle of inferior lobe. Left lung solid and in a condition of grey hepatization. Liver and kidneys shew fatty change. Spleen soft and friable.

Skall aap thickened uniformly. Dura mater normal. No adhesions anywhere. Lepto-meninges thickened and softened, from right hemisphere peeled with undue ease, except from parietal and occipital lobes.

Right hemisphere of cerebrum.-The part of this hemisphere, from and including ascending parietal gyrus backwards, as compared with the left is notably swollen, softened, and collapsed. The pia cannot be stripped therefrom. Of this the superior parietal lobule, quadrate, first annectant gyrus, and lower portion of angular gyrus bounding the parallel sulcus, are the most disintegrated. The superior parietal lobule in front of the parieto-occipital fissure, shews a spot of ochre-coloured softening sbout the size of a threepenny-piece.

The supra-marginal gyrus consists of two parallel gyri taking origin from ascending parietal ; the superior of these two is more softened than the inferior.

In the occipital lobe the superior occipital convolution is the most softened, and the mesial surface is not so eoftened as the onter. The ascending parietal is softened in its upper two-thirds only (i.e., the part above the origin of the supra-marginal gyrus). The whole convolution is atrophied. The posterior third of the gyrus fornicatus is softened. The superior temporal gyrus is softened; its posterior two-thirds especially. The remaining temporal gyri and the frontal lobe appear healthy.

On horizontal section of brain the centrum ovale majus shews 
goftening in its posterior half. On further section the softening is found to involve the white matter of the parietal lobe and of the anterior two-thirds of the occipital lobe. The posterior third of the latter, though soft in comparison with the opposite side, is distinctly less affected than the parts. first mentioned.

A section through the hemisphere passing through the three portiona of the lenticular nucleus at the level of their greatest transverse diameters, shews that the greatest softening involved the posterior third of the roof of the descending horn, and the entire roof of the posterior horn of the lateral ventricle (i.e., tapetum, optio radiations, and rectangular bundle of Wernicke). The white matter of posterior portion of occipital lobe is still of fair consistence.

On deeper section the tapetam, optic radiations, and rentangular bundle are still more disintegrated, readily breaking down under water; there is a small cyst the size of a pea in the posterior part of the roof of the descending horn near the margin.

Left hemisphere.-The convolutions are rather small otherwise there is nothing abnormal.

No ruptured or thrombosed vessels discovered. Bassil vessels hesithy.

The cerebellum, pons, medulla and spinal cord shew no naked eye evidence of disorder.

Remarks.-It is possible that the primary lesion in this case was at the seat of the cyst in the posterior part of the roof of the lateral ventricle. We may regard this as the cause of the hemianopsia which was recognized early in the case and remained unchenged throughout. The cortex of the occipital lobe and the white matter immediately underlying the same-though undoubtedly affected by softening, was probably not so to such a degree as to canse well-marked symptoms. It is a noteworthy point that, although the angular gyrus was affected to an extreme degree, there was nevertheless no crossed amblyopia. Such a condition might possibly have been present on admission, but certainly was not so as soon as the patient's mental state permitted thorough examination.

With the condition of the left papil, which was widely dilated for a fortnight before death, it is interesting to compare a case of Dr. Delépine's (read before the Pathological 
Society of London, May 20th, 1890), in which there was right homonymous hemianopsia with dilatation of the right pupil-the post-mortem appearances being almost complete destruction of the left cuneus by softening, and also softenings in the middle part of inferior frontal and posterior orbital convolutions, and another softening at the bottom of the fissure of Rolando, opposite the posterior end of superior frontal sulcus.

I regret exceedingly that sensation was not more thoroughly tested. The patient's mental state, however, and her extreme emotionalism rendered any lengthened examination requiring her attention extremely difficalt. Sensation to the prick of a pin was normally present throughout except for the first few days. This fact, as far 8.8 it goes, is opposed to the views of Munk, Luciani and others, who hold that the localization area for common sensations lies. in the central region of the cortex just beneath the parietal bone, a region in this patient extensively diseased. It is interesting, however, in connection with the experiments of Horsley and Schäfer (Trans. Royal Soc., vol. 179 (1888), B., pp. 1-45) who hold that the centre for painful and tactile sensations is in the gyrus fornicatus. Though part of that convolution was in this case disessed, there is no resson to suppose that sufficient healthy tissue was not present to functionate correctly.

As to the awkwardness and subjective sensations of the left hand, this is an interesting point, and was a prominent feature of the case throughout that period in which the patient was fairly rational. She constantly complained to the nurse that she had not proper use of her left hand, that it was numb and not like the other-this being a source of great distress to her. Her awkwardness too in bolding her sewing, and her tendency to let objects drop was remarkable, although at this time the grasp of the hand was fairly good and there was little diminution of the motor power of the arm. In this connection it is interesting to note that Bernhardt (Archiv. fur Psychiatrie, vol. xii., p. 780) reports four cases in which there were subjective affections of sensibility 


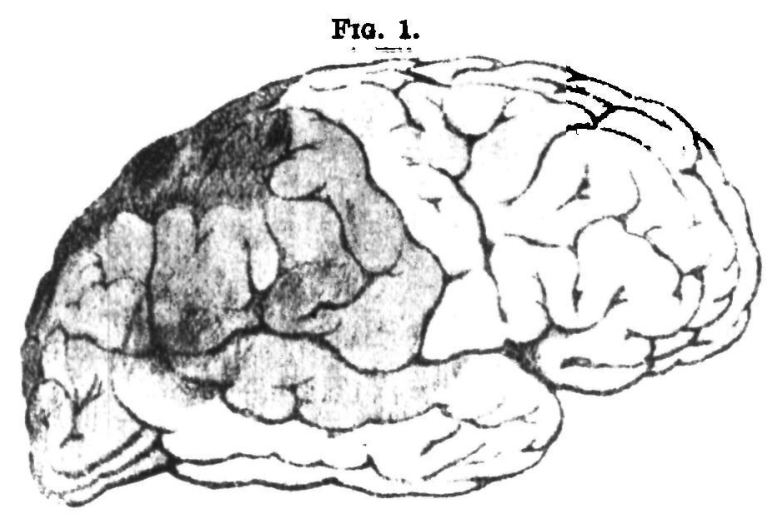

Fia. 9.
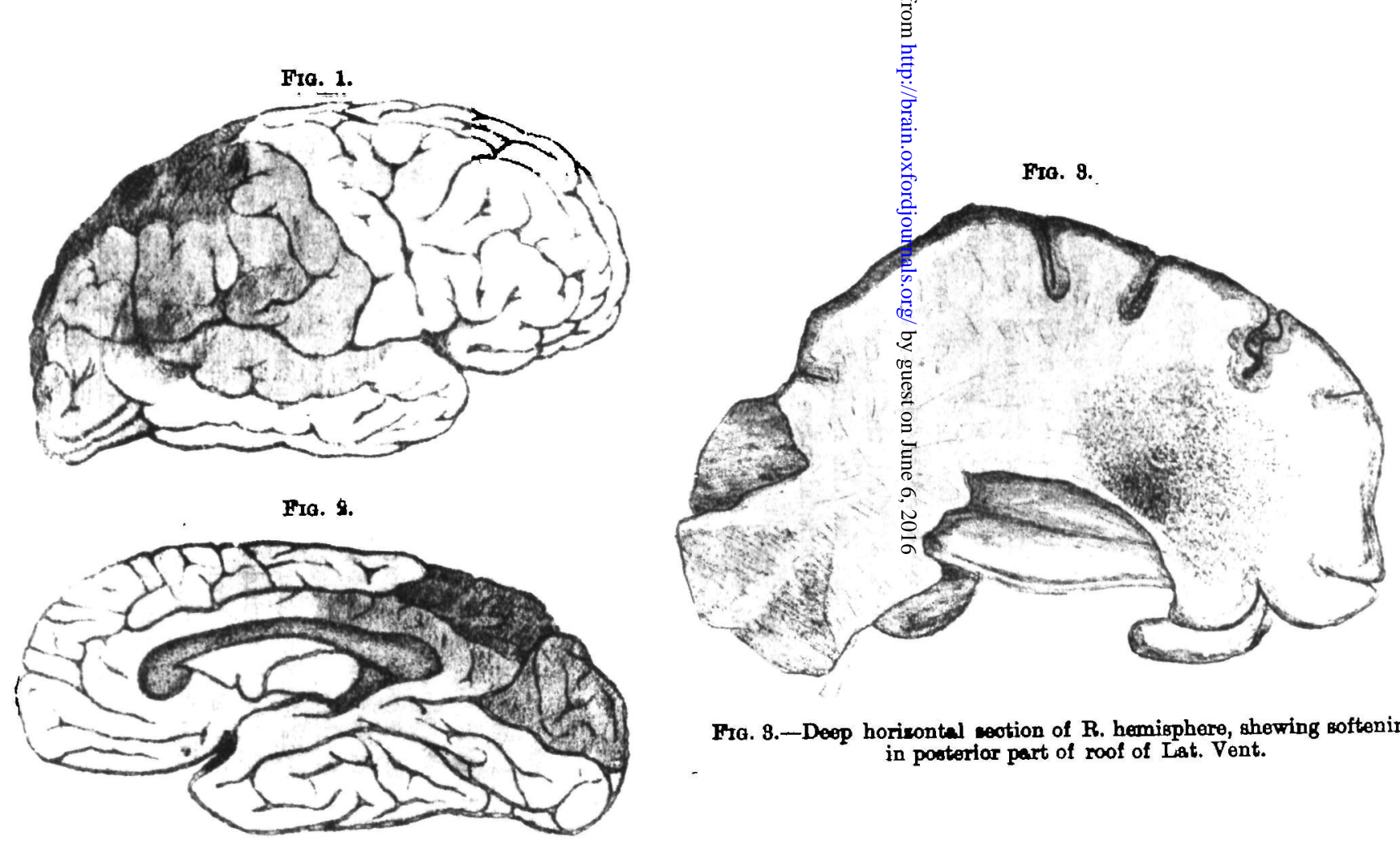

Fra. 3.-Deep horiental seotion of R. hemisphere, shewing softening in posterfor part of roof of Lat. Vent.

Fro. 1. - Erterior surface of R. hemisphere.

Fig. 2.-Mesial sorface of R. hemisphere.

Depth of shading indioates degree of softening. 
and impairment of the muscular sense associated with hemianopsia, and compares these with a case of Samelsohn's, shewing similar disturbences. He considers that these cases belong tó a type in which after an apoplectic attack the symptoms of paralysis disappear, leaving a characteristic awkwardness in the limbs of one side, especially the upper extremity. This awkwardness is further aggravated by the hemianopsia, a frequent symptom in these cases. These cases of Bernhardt's have not as yet been completed by post-mortem examination. It is worth while also to compare this case with one of Westphisl's (Charite Annalen, 1882), in which there was marked impairment of the muscular sense of the right upper extremity, essociated with diminished right-sided sensibility and bilateral right hemianopsia. The lesions found after death were softening and atrophy of the whole parietal lobe (including ascending parietal), the greater portion of the occipital and a small portion of the temporal lobe, the cortex only being involved.

The phenomena exhibited by the left plantar reflex (which was at first deficient, then present, and diseppeared totally after the second maniacal attack, about one month before deatb), may be of interest in connection with the disease of the white and grey matter of the opposite hemisphere and the macroscopically healthy basal ganglia. ${ }^{1}$

I Königgdorf (Deutsche Mad. Wochensechrift, March 8rd, 1892) reports a caso of hromorrhngio encephalitis in whioh, with much softening and blood extravesetion into the grey matter and white substenoe of the left hemisphere, the bacal ganglia also baing affected, there was threo days before death complete abonos of all supenficial reflexes on the right side. 